\title{
Infective endocarditis: trends, surgical outcomes, and controversies
}

\author{
Mahbub Jamil ${ }^{1}$, Ibrahim Sultan ${ }^{1}$, Thomas G. Gleason ${ }^{1}$, Forozan Navid ${ }^{1}$, Michael A. Fallert ${ }^{2}$, \\ Matthew S. Suffoletto ${ }^{2}$, Arman Kilic ${ }^{1}$ \\ ${ }^{1}$ Division of Cardiac Surgery, ${ }^{2}$ Division of Cardiology, University of Pittsburgh Medical Center, Pittsburgh, PA, USA \\ Contributions: (I) Concept and design: M Jamil, A Kilic; (II) Administrative support: M Fallert, T Gleason, A Kilic; (III) Provision of study materials \\ or patients: I Sultan, T Gleason, F Navid, M Fallert, M Suffoletto, A Kilic; (IV) Collection and assembly of data: All authors; (V) Data analysis and \\ interpretation: All authors; (VI) Manuscript writing: All authors; (VII) Final approval of manuscript: All authors. \\ Correspondence to: Arman Kilic, MD. Division of Cardiac Surgery, University of Pittsburgh Medical Center, 200 Lothrop Street, Suite C-700, \\ Pittsburgh, PA 15213, USA. Email: kilica2@upmc.edu.
}

\begin{abstract}
The number of hospitalizations and surgical cases of infective endocarditis (IE) are increasing. The aim of this study was to review these trends, surgical outcomes, and controversies related to IE. A search of MEDLINE of studies published between 1960 and 2018 was conducted. Search terms included "infective endocarditis", "history of", "trend", "epidemiology", “outcome", "medical management", "surgery", "indication", and "re-operative surgery", or any combination thereof. The United States has the highest incidence of IE in the world at 15 per 100,000 people, with increases in incidence due to the aging population as well as increasing rates of intravenous drug use (IVDU). National guidelines support early surgical intervention in specific clinical settings in both left and right-sided IE. However, only $11 \%$ of the evidence used in formulating guidelines for surgical therapy in IE are based on level A evidence. Ongoing controversies include whether to perform surgery in the setting of continued or recurrent IVDU in a patient with a prior valve operation, timing of surgery after acute stroke due to IE, and general indications for surgery for tricuspid valve IE. IE has a surging incidence and increasing burden on the healthcare system in the United States. Multiple controversies exist, and formulating level A evidence and multidisciplinary collaboration will be essential components to effectively treating this complex patient population.
\end{abstract}

Keywords: Infective endocarditis (IE); surgery; outcomes; trends; controversies

Submitted Apr 30, 2019. Accepted for publication Jul 24, 2019.

doi: $10.21037 /$ jtd.2019.10.45

View this article at: http://dx.doi.org/10.21037/jtd.2019.10.45

\section{Introduction}

\section{Rationale for review}

As the at-risk population including older, diabetic, dialysisdependent and intravenous drug user patients has increased, so has the incidence of IE (1). Invasive procedures leading to bacteremia are ubiquitous in modern medicine (2). Improved survival among patients with congenital cardiac anomalies and an increasing number of patients with implantable prostheses are likely to contribute to the rise in IE as well (1). Hospitalization related to IE has indeed increased between 2000 and 2011 (1) (Figure 1).
The opioid epidemic merits special attention, with approximately $10 \%$ of Americans using an illicit drug according to the National Survey on Drug Use and Health (4). The estimated number of heroin users in 2016 was higher than the number for all years between 2002 and 2013 (4). Over the last five decades, increasing numbers of IE are being attributed to intravenous drug use (IVDU) (5). IVDUs are comprising an increasing percentage of patients requiring surgery as well (6) (Figure 2). IVDU is unique not only because of its role in the causation of IE, but because of the recidivism and reinfection that is common among drug users. There is no consensus among surgeons about 


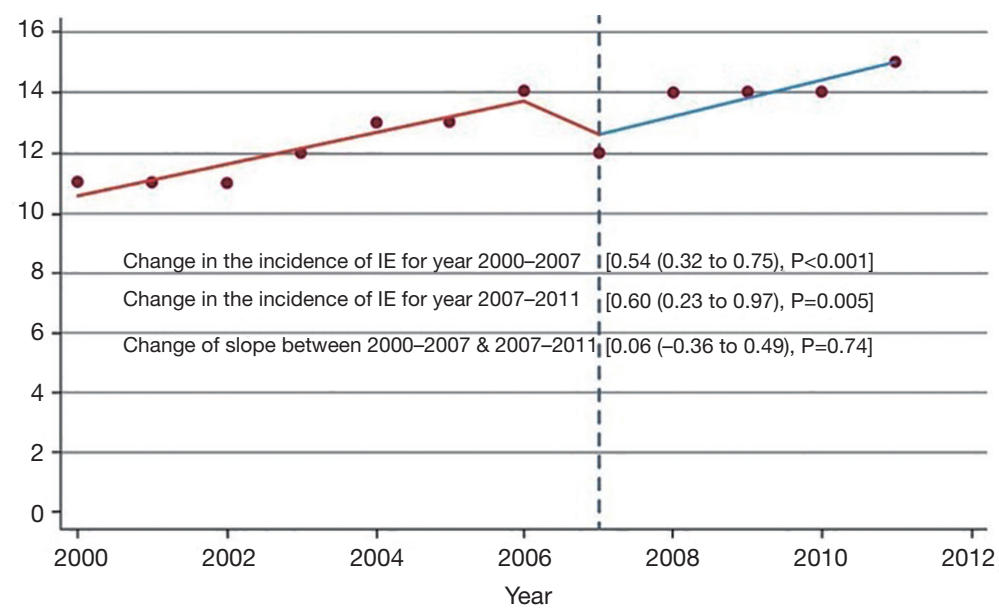

- Incidence — Fitted values of IE for year 2000-2007

_ Fitted values of IE for year 2007-2011

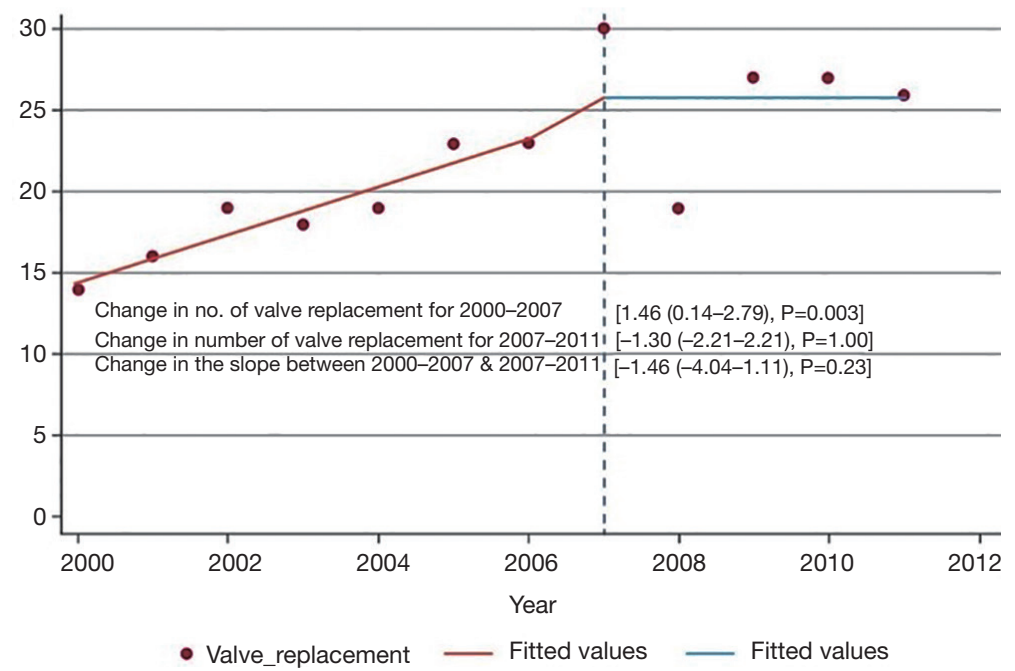

Figure 1 Increasing burden of infective endocarditis in the United States. (A) Trend in the incidence of infective endocarditis hospitalization in the U.S. (per 100,000 population), and (B) valve replacement rates for infective endocarditis (per 1,000 IE cases) in the U.S. from 2000 to 2011 (3).

how to treat patients with an ongoing addiction problem.

Besides the controversies regarding IE in drug users, multiple aspects regarding the surgical management of this condition are uncertain. The aim of this review is to provide an up-to-date summary of trends, surgical outcomes, and controversies in IE.

\section{Materials and methods}

A search was conducted on MEDLINE of studies in English language published between January 1, 1960, and March 1, 2019. The search terms included "infective endocarditis", "history of", "trend", "epidemiology", "outcome", "medical management", "surgery", "indication", and "re-operative surgery" or any combination thereof. All types of articles were included. The bibliography was further augmented by references found in the articles retrieved from MEDLINE.

\section{Results}

\section{Trends in infective endocarditis}

In the United States, the incidence of IE was 15 per 100,000 people in 2011 and has continued to increase (1,3,7-9). Several decades ago, most cases of IE in the U.S. were in the setting of rheumatic heart disease, which is still the case in many developing countries (6). Current trends 


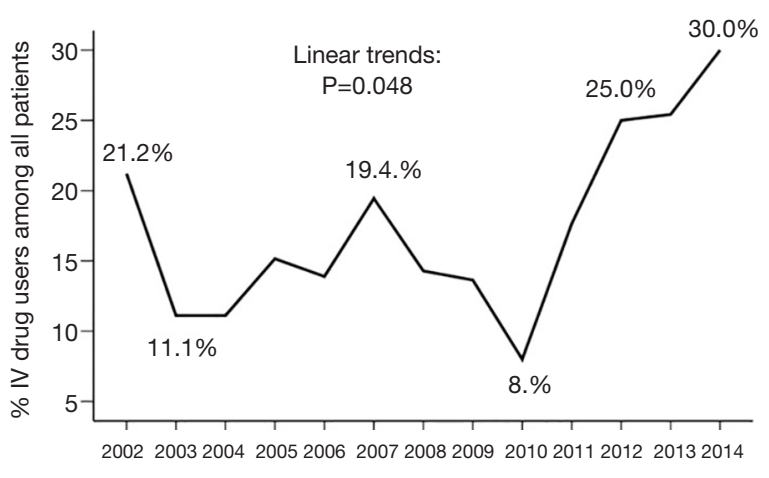

Surgical period

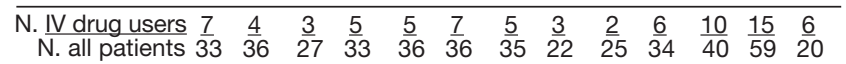

Figure 2 Trends in intravenous drug users among surgical patients with infective endocarditis at a tertiary hospital in the U.S. (6).

indicate that growth of the aging population with medical comorbidities and their associated interactions with the healthcare system are likely to contribute to the increasing incidence of IE (10-12). Patients with pre-existing cardiac valve replacements, implants or indwelling catheters rose by 42\% during 1998-2009 (7). Also noted was the increase in endocarditis related to IVDU (5).

Although the characteristics of the disease have changed significantly, the in-hospital and 6-month mortality still approaches $18 \%$ and $30 \%$, respectively $(13,14)$.

In a population-based study, the distribution of causative organisms, namely Streptococci viridans, Staphylococci, Enterococci, and HACEK did not change during 1970 through 2006, with Streptococcus predominating with a range of 30-50\% (15). From 2007 to 2013, Staphylococcus aureus led the group, comprising $33 \%$ of IE, with Streptococcus viridans dropping to $16 \%$ (16). Nationally, valve replacement rates paralleled the rising incidence of IE until 2007. In the year 2000, the valve replacement rate was 11 per 100,000 population, which increased to 30 in the year 2007. Between 2007 and 2011, the rates remained stable (1).

In a review of the global burden of IE, the United States was found to have the highest incidence whereas the Netherlands reported the lowest (11.6 vs. 1.5 cases respectively per 100,000) (17). Patients with IE in the United States also had a higher prevalence of diabetes, hemodialysis and the highest prevalence of chronic intravenous access, demonstrating a striking association with health-care-related IE (13). Staphylococcus aureus was the most common causative organism of IE globally $(10,18)$.

\section{Medical management of infective endocarditis}

Most cases of IE are treated medically (Table 1). IE from Methicillin Sensitive Staphylococcus Aureus (MSSA) responds better to oxacillin than vancomycin, indicating the need for de-escalation of antibiotics once the organism is identified (20). Daptomycin appears to be equally effective as vancomycin plus gentamicin for Staphylococcus aureus bacteremia with or without definite IE (21). Ceftriaxone alone for Streptococcal IE and ceftriaxone plus ampicillin for Enterococcal IE are adequate treatments $(19,22,23)$. Combination therapy with gentamicin has very little additional benefit compared to its higher toxicity profile $(19,23)$.

\section{Indications for surgery in infective endocarditis}

Several national and international bodies have published the indications for surgery in IE (Table 2) (24-29) with severe heart failure being the most common one $(24-26,28,29)$. However, there has been a shift in the timing of surgery for IE with preference for earlier intervention. A recent randomized clinical trial compared early surgery within 48 hours to delayed surgery at any time during the remainder of the hospitalization or follow-up (30). Those undergoing early surgery had a reduced composite rate of death, embolic event, or recurrence of IE at 6 months (3\% versus $28 \%$ ) (30). In a recent meta-analysis, among propensity-matched cohorts of patients with IE, surgery within the first 7 days was associated with a lower risk of mortality (31). Although not popularized immediately, early surgery is being adopted into practice with the median interval between admission and surgery being 4 days in some case series $(32,33)$.

\section{Surgical techniques \& outcomes}

The most important principle of surgery for IE is aggressive debridement and removal of any and all infected tissue. Attention is paid to disrupt the 'inoculum effect', where large concentrations of bacteria reside in biofilms, secluded from antibiotics (34). Treatment for aortic valve IE can include valve repair or replacement, or root reconstruction, with multiple options existing for the latter (29). Our group is aggressive in treating any involvement of the aortic root, and have recently published our experience with 138 


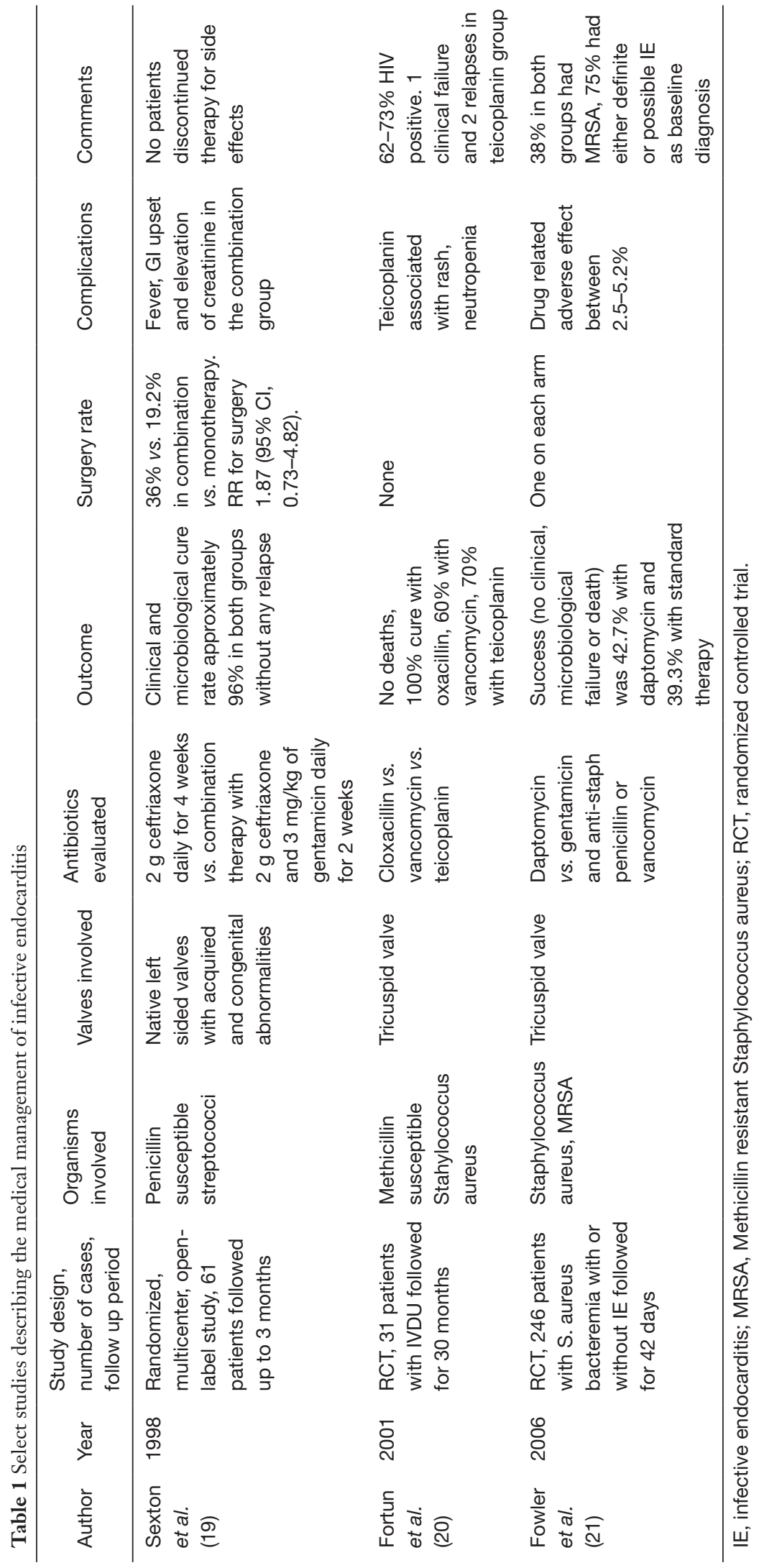


Table 2 Indications for surgery in infective endocarditis according to the 2014 American College of Cardiology/American Heart Association and the 2015 European Society of Cardiology guidelines

\begin{tabular}{ll}
\hline $\begin{array}{l}2014 \text { ACC/AHA guidelines for early } \\
\text { surgery (24) }\end{array}$ & $\begin{array}{c}2015 \text { Guidelines on the prevention, diagnosis, and treatment of infective endocarditis } \\
\text { from the ESC (25) }\end{array}$ \\
\cline { 2 - 3 } & Left sided NVE
\end{tabular}

Valve dysfunction resulting in

symptoms of HF
(I) Heart failure

Aortic or mitral NVE or PVE with severe acute regurgitation, obstruction or fistula causing refractory pulmonary edema or cardiogenic shock

Aortic or mitral NVE or PVE with severe regurgitation or obstruction causing Urgent symptoms of HF or echocardiographic signs of poor hemodynamic tolerance

(II) Uncontrolled infection

Heart block, annular or aortic abscess, or destructive penetrating lesions

Left-sided IE caused by Staphylococcal aureus, fungal, or other highly resistant organisms

Persistent infection: persistent bacteremia or fevers $>5$ to 7 days after appropriate antimicrobial therapy

PVE and relapsing infection

Recurrent emboli and persistent vegetations despite appropriate antibiotic therapy

NVE with mobile vegetations $>10 \mathrm{~mm}$ with or without clinical evidence of embolic phenomenon

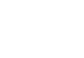

Abscess, false aneurysm, fistula, enlarging vegetation

Fungi or multi-resistant organism

Persisting positive blood cultures despite appropriate antibiotic therapy and adequate control of septic metastatic foci

PVE caused by staphylococci or non-HACEK gram-negative bacteria

(III) Prevention of embolism

Aortic or mitral NVE or PVE with persistent vegetations $>10 \mathrm{~mm}$ after one or more embolic episode despite appropriate antibiotic therapy

Aortic or mitral NVE with vegetations $>10 \mathrm{~mm}$, associated with severe valve stenosis or regurgitation, and low operative risk

Aortic or mitral NVE or PVE with isolated very large vegetations (>30 mm) (Class Ila)

Aortic or mitral NVE or PVE with isolated large vegetations (>15 mm) and no other indication for surgery (Class Ilb)

Right sided NVE

Microorganisms difficult to eradicate (e.g., fungi) or bacteremia $>7$ days despite antibiotics

Persistent tricuspid vegetation $>20 \mathrm{~mm}$ after recurrent pulmonary emboli with or without HF

Right heart failure from severe tricuspid regurgitation with poor response to diuresis

Emergency 


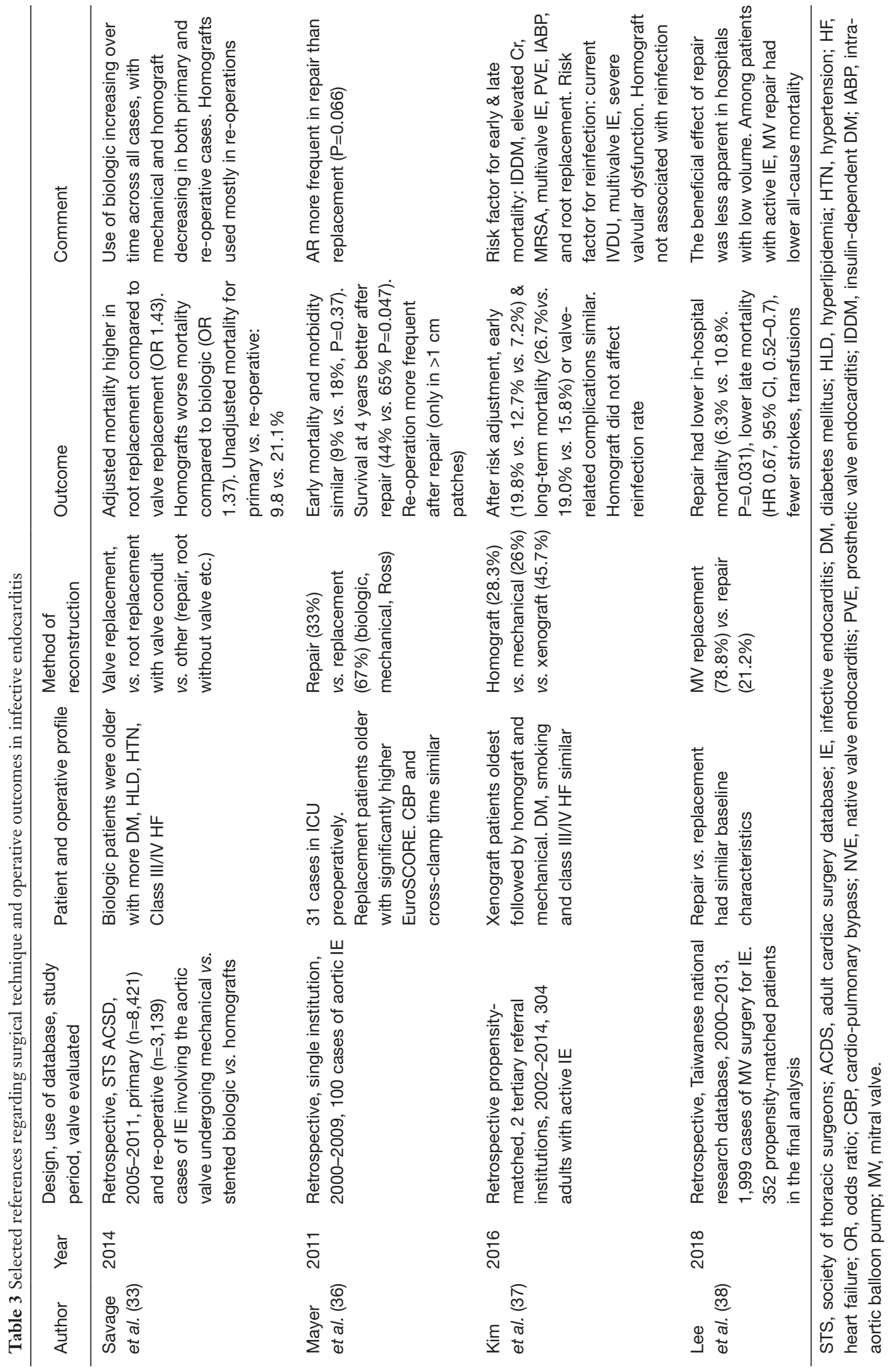


mortality was substantially higher in reoperative cases (21.1\% versus $9.8 \%)$. Another study evaluating specific types of root replacement demonstrated no differences in early and long-term mortality between homografts, xenografts, and mechanical ones (37).

In the mitral position, the benefits of repair when technically feasible have been documented in retrospective studies (Table 3) (29). A study of 352 propensity-matched cohorts comparing mitral repair versus replacement demonstrated lower in-hospital mortality, fewer strokes, lower transfusion rates, and improved long-term survival with repair (38). Double valve involvement requires complex operations and is associated with poorer outcomes (Table 3) (39). An analysis of 25 cases requiring double valve replacements demonstrated a 30-day mortality of 32\% (39).

\section{Controversies}

Surgery for infective endocarditis in the intravenous drug user

An analysis of 78 active IVDUs and 358 non-IVDUs from a prospectively maintained database between 2002 and 2014 showed that the 30-day mortality after surgery was lower for IVDUs at $3.8 \%$ compared to $13.7 \%$ for non-IVDUs, attributable to their lower surgical risk profile (40). Among IVDUs, valve re-infection (37\% by a median of 18 months) was significantly higher compared to non-IVDUs, as was the reoperation rate. In another single-institution study between 1999 and 2010, outcomes of 64 IVDUs were compared to 133 non-IVDUs (41). The pattern of valve involvement was similar with a predominance of left-sided disease in both groups. Although freedom from reoperation was similar, IVDU was an independent risk factor for diminished survival. Recurrent IE was more common among IVDUs (12.5\% vs. $2.3 \%$ ). Redo sternotomy had a mortality of $12.5 \%$ in this cohort (41). Among the medically managed cases in these two studies, half had prohibitive risk for surgery despite meeting indications, and died of their disease. Despite the reported variation in short term outcomes, long-term survival between users and non-users are not different $(40,42,43)$. Neither is compliance in follow up $(40,41)$.

The most challenging aspect in IVDU related IE is the underlying addiction. The long-term mortality in these patients are not only related to IE, but also to violence or drug overdose (44). There is no consensus among the surgeons regarding management of this critical underlying issue. Intensive rehabilitation program among patients with
IE starting as inpatients is reported with reasonable success rates $(45,46)$.

Given the scarcity of data, much of the decisionmaking regarding surgery in drug abusers is individualized and reflects the opinions of providers and institutions. Poor outcomes, risking exposure to the operating team, challenging reconstructive operations, and the elevated risk of returning to drug use are all reasons for not operating on these patients (47). At the same time, refusing to operate can be challenged from a legal and ethical standpoint. Some have argued that physicians should not venture into the moral background of a recidivist patient $(47,48)$. They have likened recurrent IE from drug-addiction to recurrent cancer where treatment would not be refused. This often leads to debate and confusion amongst the various disciplines caring for IVDU patients with IE. These issues are most relevant in the setting of reoperative surgery in the recidivist IVDU.

\section{Timing of surgery after acute stroke due to infective endocarditis}

An ischemic insult to the brain leaves a penumbra of tissue which is potentially salvageable by careful critical care management (49). Cardiopulmonary bypass and systemic anticoagulation may extend the penumbra or result in a hemorrhagic conversion. On the other hand, early surgery reduces further embolization and may prevent further valvular destruction (30).

In a study of 243 patients having surgery for IE, one third of whom had a preoperative stroke, the rate of new postoperative stroke or mortality was not different among patients with or without a preoperative stroke (50). In another retrospective review of 137 patients with non-severe stroke, surgery within 2 weeks of onset of neurological symptoms was associated with a significant benefit in reducing IE-related death $(22 \% v s .61 \%, \mathrm{P}<0.001)(51)$. Despite these findings, delayed or no cardiac surgery after stroke remains a widespread clinical practice largely owing to worsening clinical status (52).

In our practice, operations are performed early, usually within 2 weeks in patients with relatively well-preserved neurologic exam and without a large deficit or hemorrhagic component on brain imaging. For those patients with a significant clinical deficit or radiological finding, we typically will delay surgery for 4-6 weeks followed by a repeat assessment. In either case, digital subtraction angiography is essential for ruling out mycotic aneurysms which can be fatal if surgery is pursued. 


\section{Indications for surgery in tricuspid valve infective endocarditis}

In general, tricuspid valve surgery is recommended in patients who have severe tricuspid regurgitation with or without symptomatic heart failure while undergoing surgery for left-sided valvulopathy (24). In endocarditis, although size and mobility of vegetations are the most important indicators of embolism or mortality for left sided diseases, the indications for operation for the right side of the heart are not very clear $(53,54)$. Predominantly based on retrospective data, the European Society of Cardiology (ESC) task force for the management of IE recommends surgery for vegetations greater than $20 \mathrm{~mm}$ after recurrent emboli regardless of the presence of heart failure $(25,55,56)$. Other indications include microorganisms that are difficult to eradicate, persistent bacteremia and severe right-sided heart failure with poor response to diuretics. In cases where there is concomitant left-sided endocarditis, atrial septal defect, infected indwelling catheters, pacing leads and prosthetic valve endocarditis, early surgery may be considered (57,58). The American Heart Association (AHA) and the American Association of Thoracic Surgery (AATS) have endorsed these indications $(29,34)$.

Septic embolization to the lung itself is not an indication for operation in the absence of large vegetations (25). In a retrospective study of 40 patients with septic pulmonary embolism, only $27 \%$ of them were related to IE. None of these patients were treated with cardiac surgery, and most responded to antibiotics with or without pleural drainage (59). In a systemic review, among 168 cases of septic pulmonary embolism, only 7 patients required valve surgery (60). Regardless, septic embolization is one of the most commonly quoted reasons for tricuspid intervention (61).

The debate between replacement versus repair of the tricuspid valve for IE is much better informed (61-63). In a retrospective analysis of 366 patients undergoing tricuspid valve surgery, 30-day mortality after tricuspid valve repair was $14 \%$, compared to $33 \%$ for replacement $(\mathrm{P}<0.001)$. The 10-year survival was also improved for tricuspid valve repair with a tendency towards greater freedom from reoperation (61). On the other hand, a propensity-matched analysis of 315 patients and a recent meta-analysis did not find any difference in operative mortality or long-term survival for replacement versus repair $(61,63)$. However, valve repair was associated with lower recurrence of IE, lower need for reoperation, and a lower need for permanent pacemakers (61).
Our approach to tricuspid valve IE has been to operate in cases of large vegetations over $20 \mathrm{~mm}$ particularly if associated with recurrent pulmonary emboli, persistent bacteremia, or severe valvular insufficiency. In cases where the vegetations are smaller, we typically employ a period of medical management with intravenous antibiotics, followed by re-evaluation. In addition, we ensure that any other undrained areas of infections, such as an empyema, are addressed before open-heart surgery. We have anecdotally found that operating under cardiopulmonary bypass in the setting of compromised lungs, either from infection or septic embolization, frequently leads to poor oxygenation requiring extracorporeal support. Thorough drainage of the lung space and supportive care, with amelioration of respiratory failure are therefore essential prerequisites for successful lung recovery after cardiac surgery.

\section{Conclusions}

Only $11 \%$ of the evidence used in formulating guidelines for the surgical management of IE are from level A studies (64). The need for formulating level A evidence through national and international collaboration is well recognized (65). With surging numbers of IE, the unchecked opioid epidemic, and ever-increasing contact with the healthcare system, this need may soon become a dire necessity. Effective collaboration between specialties, namely cardiac surgery, cardiology, critical care, infectious disease, ethics, as well as primary care is imperative in the establishment of consensus for treating this complex patient population.

\section{Acknowledgments}

None.

\section{Footnotes}

Conflicts of Interests: Thomas Gleason: Medical Advisory Board, Abbott (Chicago, IL, USA). Arman Kilic: Medical Advisory Board, Medtronic, Inc. (Minneapolis, MN, USA). University of Pittsburgh Medical Center Heart and Vascular Institute receives research support from Medtronic, Abbott, and Boston Scientific (Marlborough, MA, USA). The other authors have no conflicts of interest to declare.

Ethical Statement: The authors are accountable for all aspects of the work in ensuring that questions related 
to the accuracy or integrity of any part of the work are appropriately investigated and resolved.

\section{References}

1. Pant S, Patel NJ, Deshmukh A, et al. Trends in infective endocarditis incidence, microbiology, and valve replacement in the United States from 2000 to 2011. J Am Coll Cardiol 2015;65:2070-6.

2. Benito N, Miró JM, de Lazzari E, et al. Health careassociated native valve endocarditis: Importance of nonnosocomial acquisition. Ann Intern Med 2009;150:586-94.

3. Fedeli U, Schievano E, Buonfrate D, et al. Increasing incidence and mortality of infective endocarditis: a population-based study through a record-linkage system. BMC Infect Dis 2011;11:48.

4. Substance Abuse and Mental Health Services Administration. (2017). Key substance use and mental health indicators in the United States: Results from the 2016 National Survey on Drug Use and Health (HHS Publication No. SMA 17-5044, NSDUH Series H-52). Rockville, MD: Center for Behavioral Health Statistics and Quality, Substance Abuse and Mental Health Services Administration. Available online: https://www.samhsa. gov/data/

5. Slipczuk L, Codolosa JN, Davila CD, et al. Infective endocarditis epidemiology over five decades: a systematic review. PLoS One 2013;8:e82665.

6. Seckeler MD, Hoke TR. The worldwide epidemiology of acute rheumatic fever and rheumatic heart disease. Clin Epidemiol 2011;3:67-84.

7. Bor DH, Woolhandler S, Nardin R, et al. Infective endocarditis in the U.S., 1998-2009: a nationwide study. PLoS One 2013;8:e60033.

8. Dayer MJ, Jones S, Prendergast B, et al. Incidence of infective endocarditis in England, 2000-13: a secular trend, interrupted time-series analysis. Lancet 2015;385:1219-28.

9. Keller K, von Bardeleben RS, Ostad MA, et al. Temporal Trends in the Prevalence of Infective Endocarditis in Germany Between 2005 and 2014. Am J Cardiol 2017;119:317-22.

10. Durante-Mangoni E, Bradley S, Selton-Suty C, et al. Current features of infective endocarditis in elderly patients: results of the International Collaboration on Endocarditis Prospective Cohort Study. Arch Intern Med 2008;168:2095-103.

11. Hoffman C, Rice D, Sung HY. Persons with chronic conditions. Their prevalence and costs. JAMA
1996;276:1473-9.

12. Friedman ND, Kaye KS, Stout JE, et al. Health care-associated bloodstream infections in adults: a reason to change the accepted definition of community-acquired infections. Ann Intern Med 2002;137:791-7.

13. Murdoch DR, Corey GR, Hoen B, et al. Clinical presentation, etiology, and outcome of infective endocarditis in the 21st century: the International Collaboration on Endocarditis-Prospective Cohort Study. Arch Intern Med 2009;169:463-73.

14. Park LP, Chu VH, Peterson G, et al. Validated Risk Score for Predicting 6-Month Mortality in Infective Endocarditis. J Am Heart Assoc 2016;5:e003016.

15. Correa de Sa DD, Tleyjeh IM, Anavekar NS, et al. Epidemiological trends of infective endocarditis: a population-based study in Olmsted County, Minnesota. Mayo Clin Proc 2010;85:422-6.

16. DeSimone DC, Tleyjeh IM, Correa de Sa DD, et al. Temporal trends in infective endocarditis epidemiology from 2007 to 2013 in Olmsted County, MN. Am Heart J 2015;170:830-6.

17. Bin Abdulhak AA, Baddour LM, Erwin PJ, et al. Global and regional burden of infective endocarditis, 19902010: a systematic review of the literature. Glob Heart 2014;9:131-43.

18. Vogkou CT, Vlachogiannis NI, Palaiodimos L, et al. The causative agents in infective endocarditis: a systematic review comprising 33,214 cases. Eur J Clin Microbiol Infect Dis 2016;35:1227-45.

19. Sexton DJ, Tenenbaum MJ, Wilson WR, et al. Ceftriaxone once daily for four weeks compared with ceftriaxone plus gentamicin once daily for two weeks for treatment of endocarditis due to penicillin-susceptible streptococci. Endocarditis Treatment Consortium Group. Clin Infect Dis 1998;27:1470-4.

20. Fortún J, Navas E, Martínez-Beltrán J, et al. Short-course therapy for right-side endocarditis due to Staphylococcus aureus in drug abusers: cloxacillin versus glycopeptides in combination with gentamicin. Clin Infect Dis 2001;33:120-5.

21. Fowler VG Jr, Boucher HW, Corey GR, et al. Daptomycin versus standard therapy for bacteremia and endocarditis caused by Staphylococcus aureus. N Engl J Med 2006;355:653-65.

22. Francioli P, Etienne J, Hoigné R, et al. Treatment of streptococcal endocarditis with a single daily dose of ceftriaxone sodium for 4 weeks. Efficacy and outpatient treatment feasibility. JAMA 1992;267:264-7. 
23. Fernández-Hidalgo N, Almirante B, Gavaldà J, et al. Ampicillin plus ceftriaxone is as effective as ampicillin plus gentamicin for treating enterococcus faecalis infective endocarditis. Clin Infect Dis 2013;56:1261-8.

24. Nishimura RA, Otto CM, Bonow RO, et al. 2014 AHA/ ACC Guideline for the Management of Patients With Valvular Heart Disease: executive summary: a report of the American College of Cardiology/American Heart Association Task Force on Practice Guidelines. Circulation 2014;129:2440-92.

25. Habib G, Lancellotti P, Antunes MJ, et al. 2015 ESC Guidelines for the management of infective endocarditis: The Task Force for the Management of Infective Endocarditis of the European Society of Cardiology (ESC). Endorsed by: European Association for Cardio-Thoracic Surgery (EACTS), the European Association of Nuclear Medicine (EANM). Eur Heart J 2015;36:3075-128.

26. Bonow RO, Carabello BA, Kanu C, et al. ACC/AHA 2006 guidelines for the management of patients with valvular heart disease: a report of the American College of Cardiology/American Heart Association Task Force on Practice Guidelines (writing committee to revise the 1998 Guidelines for the Management of Patients With Valvular Heart Disease): developed in collaboration with the Society of Cardiovascular Anesthesiologists: endorsed by the Society for Cardiovascular Angiography and Interventions and the Society of Thoracic Surgeons. Circulation 2006;114:e84-231.

27. Gould FK, Denning DW, Elliott TS, et al. Guidelines for the diagnosis and antibiotic treatment of endocarditis in adults: a report of the Working Party of the British Society for Antimicrobial Chemotherapy. J Antimicrob Chemother 2012;67:269-89.

28. Habib G, Hoen B, Tornos P, et al. Guidelines on the prevention, diagnosis, and treatment of infective endocarditis (new version 2009): the Task Force on the Prevention, Diagnosis, and Treatment of Infective Endocarditis of the European Society of Cardiology (ESC). Endorsed by the European Society of Clinical Microbiology and Infectious Diseases (ESCMID) and the International Society of Chemotherapy (ISC) for Infection and Cancer. Eur Heart J 2009;30:2369-413.

29. AATS Surgical Treatment of Infective Endocarditis Consensus Guidelines Writing Committee Chairs, Pettersson GB, Coselli JS, et al. 2016 The American Association for Thoracic Surgery (AATS) consensus guidelines: Surgical treatment of infective endocarditis: Executive summary. J Thorac Cardiovasc Surg 2017;153:1241-58.e29.

30. Kang DH, Kim YJ, Kim SH, et al. Early surgery versus conventional treatment for infective endocarditis. N Engl J Med 2012;366:2466-73.

31. Anantha Narayanan M, Mahfood Haddad T, Kalil AC, et al. Early versus late surgical intervention or medical management for infective endocarditis: a systematic review and meta-analysis. Heart 2016;102:950-7.

32. Iung B, Doco-Lecompte $\mathrm{T}$, Chocron $\mathrm{S}$, et al. Cardiac surgery during the acute phase of infective endocarditis: discrepancies between European Society of Cardiology guidelines and practices. Eur Heart J 2016;37:840-8.

33. Savage EB, Saha-Chaudhuri P, Asher CR, et al. Outcomes and prosthesis choice for active aortic valve infective endocarditis: analysis of the Society of Thoracic Surgeons Adult Cardiac Surgery Database. Ann Thorac Surg 2014;98:806-14.

34. Baddour LM, Wilson WR, Bayer AS, et al. Infective Endocarditis in Adults: Diagnosis, Antimicrobial Therapy, and Management of Complications: A Scientific Statement for Healthcare Professionals From the American Heart Association. Circulation 2015;132:1435-86.

35. Sultan I, Bianco V, Kilic A, et al. Aortic root replacement with cryopreserved homograft for infective endocarditis in the modern North American opioid epidemic. J Thorac Cardiovasc Surg 2019;157:45-50.

36. Mayer K, Aicher D, Feldner S, et al. Repair versus replacement of the aortic valve in active infective endocarditis. Eur J Cardiothorac Surg 2012;42:122-7.

37. Kim JB, Ejiofor JI, Yammine M, et al. Are homografts superior to conventional prosthetic valves in the setting of infective endocarditis involving the aortic valve? J Thorac Cardiovasc Surg 2016;151:1239-46, 1248.e1-2.

38. Lee HA, Cheng YT, Wu VC, et al. Nationwide cohort study of mitral valve repair versus replacement for infective endocarditis. J Thorac Cardiovasc Surg 2018;156:1473-83.e2.

39. Davierwala PM, Binner C, Subramanian S, et al. Double valve replacement and reconstruction of the intervalvular fibrous body in patients with active infective endocarditis. Eur J Cardiothorac Surg 2014;45:146-52.

40. Kim JB, Ejiofor JI, Yammine M, et al. Surgical outcomes of infective endocarditis among intravenous drug users. J Thorac Cardiovasc Surg 2016;152:832-41.e1.

41. Rabkin DG, Mokadam NA, Miller DW, et al. Longterm outcome for the surgical treatment of infective endocarditis with a focus on intravenous drug users. Ann Thorac Surg 2012;93:51-7. 
42. Carozza A, De Santo LS, Romano G, et al. Infective endocarditis in intravenous drug abusers: patterns of presentation and long-term outcomes of surgical treatment. J Heart Valve Dis 2006;15:125-31.

43. Thalme A, Westling K, Julander I. In-hospital and longterm mortality in infective endocarditis in injecting drug users compared to non-drug users: a retrospective study of 192 episodes. Scand J Infect Dis 2007;39:197-204.

44. Joe GW, Simpson DD. Mortality rates among opioid addicts in a longitudinal study. Am J Public Health 1987;77:347-8.

45. Suzuki J. Medication-assisted treatment for hospitalized patients with intravenous-drug-use related infective endocarditis. Am J Addict 2016;25:191-4.

46. Liebschutz JM, Crooks D, Herman D, et al. Buprenorphine treatment for hospitalized, opioiddependent patients: a randomized clinical trial. JAMA Intern Med 2014;174:1369-76.

47. DiMaio JM, Salerno TA, Bernstein R, et al. Ethical obligation of surgeons to noncompliant patients: can a surgeon refuse to operate on an intravenous drug-abusing patient with recurrent aortic valve prosthesis infection? Ann Thorac Surg 2009;88:1-8.

48. Hull SC, Jadbabaie F. When Is Enough Enough? The Dilemma of Valve Replacement in a Recidivist Intravenous Drug User. Ann Thorac Surg 2014;97:1486-7.

49. Mendez AA, Samaniego EA, Sheth SA, et al. Update in the Early Management and Reperfusion Strategies of Patients with Acute Ischemic Stroke. Crit Care Res Pract 2018;2018:9168731.

50. Ghoreishi M, Foster N, Pasrija C, et al. Early Operation in Patients With Mitral Valve Infective Endocarditis and Acute Stroke Is Safe. Ann Thorac Surg 2018;105:69-75.

51. Murai R, Funakoshi S, Kaji S, et al. Outcomes of early surgery for infective endocarditis with moderate cerebral complications. J Thorac Cardiovasc Surg 2017;153:831-40.e8.

52. Garcia-Cabrera E, Fernandez-Hidalgo N, Almirante $B$, et al. Neurological complications of infective endocarditis: risk factors, outcome, and impact of cardiac surgery: a multicenter observational study. Circulation 2013;127:2272-84.

53. Rohmann S, Erbel R, Darius H, et al. Prediction of rapid versus prolonged healing of infective endocarditis by monitoring vegetation size. J Am Soc Echocardiogr $1991 ; 4: 465-74$.
54. Martín-Dávila P, Navas E, Fortún J, et al. Analysis of mortality and risk factors associated with native valve endocarditis in drug users: the importance of vegetation size. Am Heart J 2005;150:1099-106.

55. Hecht SR, Berger M. Right-sided endocarditis in intravenous drug users. Prognostic features in 102 episodes. Ann Intern Med 1992;117:560-6.

56. Robbins MJ, Frater RW, Soeiro R, et al. Influence of vegetation size on clinical outcome of right-sided infective endocarditis. Am J Med 1986;80:165-71.

57. Akinosoglou K, Apostolakis E, Koutsogiannis N, et al. Right-sided infective endocarditis: surgical management. Eur J Cardiothorac Surg 2012;42:470-9.

58. Dawood MY, Cheema FH, Ghoreishi M, et al. Contemporary outcomes of operations for tricuspid valve infective endocarditis. Ann Thorac Surg 2015;99:539-46.

59. Goswami U, Brenes JA, Punjabi GV, et al. Associations and outcomes of septic pulmonary embolism. Open Respir Med J 2014;8:28-33.

60. Ye R, Zhao L, Wang C, et al. Clinical characteristics of septic pulmonary embolism in adults: a systematic review. Respir Med 2014;108:1-8.

61. Yanagawa B, Elbatarny M, Verma S, et al. Surgical Management of Tricuspid Valve Infective Endocarditis: A Systematic Review and Meta-Analysis. Ann Thorac Surg 2018;106:708-14.

62. Guenther T, Noebauer C, Mazzitelli D, et al. Tricuspid valve surgery: a thirty-year assessment of early and late outcome. Eur J Cardiothorac Surg 2008;34:402-9; discussion 409.

63. Moraca RJ, Moon MR, Lawton JS, et al. Outcomes of tricuspid valve repair and replacement: a propensity analysis. Ann Thorac Surg 2009;87:83-8; discussion 88-9.

64. Tricoci P, Allen JM, Kramer JM, et al. Scientific evidence underlying the ACC/AHA clinical practice guidelines. JAMA 2009;301:831-41.

65. Bando K. Proposal for building an infrastructure for international randomized, control trials and a comprehensive registry of infective endocarditis. J Thorac Cardiovasc Surg 2018;155:73-74.

Cite this article as: Jamil M, Sultan I, Gleason TG, Navid F, Fallert MA, Suffoletto MS, Kilic A. Infective endocarditis: trends, surgical outcomes, and controversies. J Thorac Dis 2019;11(11):4875-4885. doi: 10.21037/jtd.2019.10.45 